\title{
A Retrospective Study of the Autism Spectrum Disease (ASD): A Review of Literature and Management Techniques of ASD
}

\author{
Rajkishor Chaudhary ${ }^{1 *}$, Gaukaran Janghel ${ }^{2}$
}

\section{ABSTRACT}

Education brings knowledge and it is an important part of human development education is the natural, harmonious and progressive development of man's innate powers. From the reviewed studies, the studies on educational needs aspects focused on Enhancing Communication Skills, Enhancing Social skills, Studies on Retrospective focused in this purpose we are searches in the published and non-published article and research paper from different journals, books, and online database. In this studies total of 11 studies have been reviewed and discussed to obtain an understanding of the area under consideration. Among them 3 studies are related to educational needs aspects, 3 studies related to communication need, 4 studies related to Retrospective aspects. Out of 11 studies 3 of the studies were Indian and 9 of the studies were foreign studies.

Keywords: Autism Spectrum Disorder, Retrospective Study

Education brings knowledge and it is an important part of human development education is the natural, harmonious and progressive development of man's innate powers (Pestalozzi). Special education is the branch of this education which deals with exceptionality. Exceptional children and youth are those "who deviate from the normal population in they require special social and educational services to develop their maximum capacity". It is well known that education is a fundamental right of every child. According to the federal government (IDEA) exceptional children in includes children with mental retardation, deaf-blindness, emotional disturbances, hearing impairment, specific learning disability, speech and language impairment, traumatic brain injury, giftedness, visual impairment and autism.

The Individuals with Disabilities Education Act (IDEA) entitles children with autism to an education that is comparable in term of skills and information to children who are not disabled but the difference is that autistic children often need additional educational activities to help them develop. The additional training that autistic children often need includes communication

\footnotetext{
${ }^{1}$ Assistant Professor Of Special Education, Aakanksha Collage Of Special Education, Raipur, India

${ }^{2}$ Assistant Professor, Aakanksha College Of Special Education, Raipur, India

*Responding Author

(c) 2016 I R Chaudhary; licensee IJIP. This is an Open Access Research distributed under the terms of the Creative Commons Attribution License (http://creativecommons.org/licenses/by/2.0), which permits unrestricted use, distribution, and reproduction in any Medium, provided the original work is properly cited.
} 


\section{A Retrospective Study of the Autism Spectrum Disease (ASD): A Review of Literature and Management Techniques of ASD}

skills, social skills, language skills, behavioural issues and leisure skills. Without a firm grasp of these skills, children with autism would have difficulty learning their academic subjects. For this reason, additional assistance is often needed in these areas to allow the child to meet their academic goals.

The autism spectrum currently affects between 60 and 100 per 10,000 children under the age of eight (MRC, 2001; NIASA, 2003). In England, the number of pupils with Statements of special educational needs that have a primary special education need of autism spectrum disorder increased form 24,000 in 2004 to 35,000 in 2008 (DCSF, 2008a). Out of these pupils, nearly $70 \%$ of pupils on the autism spectrum attend mainstream school (DCSF, 2008a). This highlights the need to assess the evidence base in order to identify notions of 'best practice' in the education of children and young people on the autism spectrum in mainstream settings.

There are many different types of interventions that have been developed specifically for children on the autism spectrum, ranging from approaches such as the TEAACH approach (Treatment and Education of Autistic and Communication related Handicapped Children), which originated in North Carolina (Scholar \& Mesibov, 1995), to approaches such as the Picture Exchange Communication System (Bondy \& Frost, 1994) or Social Stories (Gray, 1994). These interventions provide parents and practitioners with powerful tools and strategies for meeting the needs of children on the autism spectrum. This is positive. However, it can be problematic if practitioners look to those models and interventions without first having a good understanding of the autism spectrum or without addressing the individual child's needs and learning context.

\section{CAUSES OF ASD}

Autism was first described in the early 1940s by Dr. Leo Kanner. Until the 1960s, it was thought to be caused by poor parenting that might have included neglect and withdrawal of affection. Since the 1970s, it has been clear to researchers and clinicians that autism is not caused by such emotional abuse. Children who are subject to such neglect or abuse might exhibit similar behavioural disturbances, but these are distinct from ASD.

Individuals with ASD have been shown to have structural and chemical differences in their brains compared to normally developing peers. However, the manner by which these differences come about is the subject of considerable research. Autism and ASD are believed now to be multifactorial disorders; that is, many factors come into play when determining the cause. These factors include complex genetic interactions, nutritional deficiencies or overloads, pre- and postnatal exposure to chemicals or viruses, errors during the embryonic neural tube closure process, dysfunctional immune systems, and even allergies. The issue of vaccines as a possible cause of ASD will also be discussed here, although there is now sufficient scientific evidence for most researchers to dismiss the argument. 


\section{A Retrospective Study of the Autism Spectrum Disease (ASD): A Review of Literature and Management Techniques of ASD}

\section{A. Genetics}

There is considerable evidence that ASD is determined largely by genetics, but the issue is very complex. Numerous studies involving families in which more than one member is affected with ASD have provided enough information for researchers to conclude that: the identical twin of an individual with ASD has a better than $90 \%$ chance of also being affected; a fraternal twin or sibling of an affected individual has a 15\% chance of having ASD; and an ASD parent has a 10\% chance that his or her offspring will also have ASD.

The difference between the probabilities that identical versus fraternal twins will be affected by ASD indicates that genetics is a strong determinant, since both identical and fraternal twins experience the same in utero environment while only the identical twins share the same genetics. The observation that the identical twin of an individual with ASD is not at a $100 \%$ risk of also having ASD indicates, however, that there is more at play than simply genetics. Finally, the broad range of symptoms, even within a family, has led researchers to conclude that multiple genes, possibly even an unfortunate combination of normal ones, are involved in causing ASD. Many of the physiological observations reported by researchers, such as faulty neural tube closure at the embryonic stage and abnormal brain physiology, may in fact be the result of the ASD genes involved. Research into the genetics of ASD will be discussed in more detail later.

\section{B. Environmental Pollutants and Toxins}

Another factor that may be a potential cause of ASD is exposure to pollutants and toxins during foetal development. This possibility has been put forward due to the perceived increase in the prevalence of ASD over recent years, the belief that it has appeared as a disorder only recently, and the detection of geographic areas with slightly higher rates of ASD. Although no conclusive evidence has been found to date, this has become an active area of research; see the section below entitled "Current Research Projects."

\section{Vaccines, Viruses and Impaired Immune Systems}

In recent years, considerable public attention was given to the theory that the measles-mumpsrubella (MMR) vaccine, or other combination of vaccines, potentially contributed to the development of autism due to the mercury-containing thimerosal used as a preservative. This theory came about during research into whether this vaccine could be linked to the intestinal disorder Crohn's disease, and involved a very small number of children. Since that time, no scientific evidence has emerged to substantiate the theory. On the contrary, the observation that the introduction of the MMR vaccine was not followed by a surge in ASD diagnoses is just one of the epidemiological findings that have essentially disproved the vaccine theory. Canada's National Advisory Committee on Immunization issued updated recommendations for thimerosalcontaining vaccines in December 2005. The updated recommendations, based on the best available scientific evidence, reaffirm the Committee's earlier position that "there is no 


\section{A Retrospective Study of the Autism Spectrum Disease (ASD): A Review of Literature and Management Techniques of ASD}

legitimate safety reason to avoid the use of thimerosal-containing products.” Nevertheless, due to the speculation and public criticism, thimerosal has been phased out in most vaccines and very few available in Canada still contain the preservative.

Exposure to cytomegalovirus and rubella during early pregnancy is thought by some researchers to increase the risk of having an autistic child. Possibly related to viral exposure is the observation that many autistic individuals have impaired immune systems. Some researchers believe that viral infections may be responsible for the fact that many ASD individuals have a decreased number of helper T-cells, which assist the immune system in fighting infections. Other findings indicate that early immune response to viral infection, either in utero or during infancy, may somehow cause the immune system to malfunction, resulting in the production of antibodies against the foetus' or child's own brain tissue and hence in the brain damage seen in ASD.

\section{Nutrition, Food Sensitivities and Digestive Disorders}

Some attention has recently focused on digestive problems and sensitivities to certain foods, not so much as potential causes of ASD but as possibly contributing to autistic behaviour. Researchers have found that autistic individuals are unable to break down, or digest properly, two kinds of protein: gluten, found in grains like wheat, barley and oats; and casein, found in dairy products. Further aggravating the problem is the fact that these same foods tend to be craved by ASD individuals. Eliminating or restricting the presence of these proteins in the diet of ASD people has been found to improve their health and behaviour in many cases.

Further, scientists have noted that some ASD people have excessive amounts of the yeast Candida albicans in their intestinal tract. As yeast grows, it releases toxins into the bloodstream, and high levels of the yeast in turn mean higher toxin levels. These toxins are thought to contribute to autistic behaviours. However, the reason for elevated C. albicans levels in the intestines has not been identified.

Finally, some improvements in communication skills, awareness and attention have been noted as a result of supplementing the diet of ASD individuals with magnesium, vitamin B6 and dimethyl glycine. These observations are consistent with the other digestive abnormalities seen in autistic people and may be related to poor intestinal absorption of some nutrients. Other nutritional factors that may be involved include a lack of essential minerals such as calcium, zinc, iodine, lithium and potassium.

\section{E. Additional in utero Factors}

Although not currently a primary focus of major research, several factors experienced by the embryo or foetus have been identified as potential causes of autism. Studies have suggested that major psychological stress, such as death of a loved one, during the 24th to 28th week of pregnancy increases a woman's chance of having an autistic child. This timing agrees with the 


\section{A Retrospective Study of the Autism Spectrum Disease (ASD): A Review of Literature and Management Techniques of ASD}

development of the foetal cerebellum, that portion of the brain that is structurally different in autistic children. It is possible that expression of some of the "autistic genes" is induced, or activated, by stress. Several genes have been identified that are induced following different types of stressors.

Other research has explored the role of substances intentionally consumed by expectant women that may have a toxic effect. Retinoids have been studied in this respect. Thousands of retinoids have been either isolated or synthesized for potential pharmaceutical applications, mostly for treatment of skin diseases and cancer. Other retinoids may be environmental pollutants. Some researchers believe that these substances could cause brain abnormalities that resemble those seen in autism. Retinoids may also be taken as nutritional supplements, such as retinoic acid and vitamin A. While a deficiency of vitamin A could lead to abnormal neural tube closure in the embryo - thus providing a possible link to autism - studies have suggested that excesses of these compounds may also produce birth defects. That is, animal model studies have suggested that brain damage similar to that seen in ASD may be caused by overexposure to retinoids. The genetics of autism and the role of retinoids in ASD have recently overlapped with the discovery that retinoids are known modifiers of the proposed autism genes that are members of a family of genes known as the Hox genes. This suggests that an individual's predisposition to autism by virtue of carrying an "autism gene" may be further endangered by exposure to retinoids that modify the gene, producing an autistic behaviour or physiological marker.

\section{Incidence and Prevalence}

Communication Facts: Special Populations: Autism - 2008 Edition

Autism is a neurodevelopment disorder defined by impairments in social and communication development, accompanied by stereotyped patterns of behavior and interest (1). ASHA-certified speech-language pathologists screen for, evaluate, and treat speech and language disorders secondary to the primary diagnosis of autism. Speech-language pathologists may also be part of the interdisciplinary team involved with the diagnosis of autism (2).

\section{General Demographics}

Controversy surrounds reports on the incidence and prevalence of autism and autistic spectrum disorders. Even more confusing is the concern regarding an apparent increase in the prevalence of the condition, often attributed to a variety of possible causes. Several possible explanations exist, including changes in diagnostic criteria, variations in case finding and identification between different epidemiologic studies, genetic and/or environmental sources, greater public and professional awareness, wider availability of treatment services, and increases in the actual incidence of the disorders (3-8).

- Prevalence figures vary widely within the medical and allied health literature. The stated range for the prevalence of autism may be from less than 1 to 1,300 per 10,000 individuals $(4,6,7,9-14)$. 


\section{A Retrospective Study of the Autism Spectrum Disease (ASD): A Review of Literature and Management Techniques of ASD}

- Autism is three to five times more common in males than in females (15).

- Evidence is growing too strongly support genetic inheritance as an important contributor to autism. Scientists estimate that, in families with one child with autism, the risk of having a second child with the disorder is approximately $2 \%$ to $8 \%$, which is greater than the risk for the general population (16-18).

- The number of children with disabilities, ages 3-21, served in the public schools under the Individuals with Disabilities Education Act (IDEA) Part B in fall 2002 was 6,606,702 (in the 50 states, D.C., and P.R.). Of these children, 136,986 (2\%) received services for autism-related disorders (19). Data by disability are not reported by the Department of Education for children between birth and age 3.

\section{Pervasive Developmental Disorder}

Pervasive Developmental Disorder (PDD) includes five diagnoses under the autism spectrum: autistic disorder, Asperger's syndrome, childhood disintegrative disorder, Rett's Syndrome, and Pervasive Developmental Disorder-Not Specified (PDD-NOS) (2, 18).

- PDD is characterized by severe and pervasive impairment in general areas of development, including reciprocal social interaction skills and communication skills (20).

- Actual speech production may be impaired: speech may be robotic, monotonous, and with little change in pitch or expression. There can also be problems with pronunciation (21).

- Prevalence rates for PDD vary widely within the pertinent literature, ranging from 18.7 to 60 per 10,000 (22, 23).

- Estimating the prevalence of PDD in children and adolescents with mental retardation is complicated. The literature reports prevalence rates ranging from $3 \%$ through $50 \%$. The differences in the estimated prevalence rates are related, in part, to the concept of PDD (24).

\section{Autistic Disorder}

Autistic Disorder begins in childhood. It is marked by the presence of markedly abnormal or impaired development in social interaction and communication and a markedly restricted repertoire of activity and interest. When speech develops, the pitch, intonation, rate, rhythm, or stress may be abnormal (e.g., monotony, inappropriate tone with context) (20). Manifestations of the disorder vary greatly depending on the developmental level and chronological age of the individual (11). Several studies indicate that the prevalence rate for autistic disorder ranges from between .2 and .6 per 10,000 individuals (10,11, and 20).

\section{Diagnosis}

Diagnosis is based on behaviour, not causes or mechanism. Autism is defined in the DSM-IV-TR as exhibiting at least six symptoms total, including at least two symptoms of qualitative impairment in social interaction, at least one symptoms of qualitative impairment in 


\section{A Retrospective Study of the Autism Spectrum Disease (ASD): A Review of Literature and Management Techniques of ASD}

communication, and at least one symptom of restricted and repetitive behaviour. Sample symptoms include lack of social or emotional reciprocity, stereotype and repetitive use of language or idiosyncratic language, persistent preoccupation with parts of objective. Onset must be prior to age three years, with delays or abnormal functioning in either social interaction, language as used in social communication, or symbolic or imaginative play. The disturbance must not be better accounted for by Rett syndrome or childhood disintegrative disorder ICD-10 uses essentially the same definition. There are no medical tests for diagnosing Autism.

In a recently published study Malhotra et al (2003) compared the socio-demographic and clinical profile of PPD patients registered at CAP (child and Adolescent Psychiatry Clinic) Clinic, PostGraduation Institute of Medical Education and Research (PGIMER), and Chandigarh between 1989 and 1992. Out of 2942 cases 46 cases (1.6\%) met ICD-10 criteria for different PPDs. 22 cases were of typical autism, 12 cases each were of Childhood Disintegrative Disorders (CDD) and other PDDs. 5 cases met criteria for atypical autism, 4 were of Asperger's syndrome and the rest were of Rett's syndrome $(n=2)$ and PDD unspecified $(n=)$. Relatively high promotion (26\%) of cases of CDD is notable as it has been suggest that CDD is only about one-tenth as common as autism. $78 \%$ of the total sample was male, all exhibited classical symptoms and temperamental variations ware noted in the areas of activity, rhythmicity and attention span in most of the cases. Comparisons between the three groups of typical autism ( $n=22)$, CDD ( $n=12)$ and other PPDs $(n=12)$ on various socio demographic and clinical parameters showed significant different on various socio clinical parameters lie socioeconomic status, onset of illness, age at onset, temperamental variable neurotic traits, delay in milestone and intelligence quotient

\section{Diagnosis criteria}

Profiles of characteristic necessary for a diagnosis of classic autism or an ASD are called diagnostic criteria. These appear within general systems for the classification and diagnosis of psychological problems such as the Diagnosis and Statistical Manual prepared by the American Psychiatric Association (last revised in 2000 and knows as DSM-IV-TR), and the International Classification of Diseases, prepared by the World Health Organization (currently in its tenth edition and knows as ICD-10).

Criteria for diagnosis of Autism according to DSM-IV-TR

A) A total of six (or more) items from (1), (2) and (3), with at least 


\section{A Retrospective Study of the Autism Spectrum Disease (ASD): A Review of Literature and Management Techniques of ASD}

\section{Screening}

The first step in the diagnosis of autism is screening. Early detection enables referral to intervention services and for family support, with the goal of an improved outcome. Several screening instruments have been developed to quickly gather information about a child's social and communicative development. Among them are the Checklist of Autism in Toddlers (CHAT), the modified Checklist for Autism in Toddlers (M-CHAT), the Screening Tool for Autism in Two-Year-Olds (STAT), and the Social Communication Questionnaire (SCQ) for children 4 years of age and older.

Some screening instruments rely solely on parent responses to a questionnaire, and some rely on a combination of parent report and observation. Key items on these instruments that appear to differentiate children with autism from other groups before the age of 2 include pointing and pretend play. Screening instruments do not provide individual diagnosis but serve to assess the need for referral for possible diagnosis of ASD. These screening methods may not identify children with mild ASD, such as those with high-functioning autism or Asperger syndrome.

During the last few years, screening instruments have been devised to screen for Asperger syndrome and higher functioning autism. The Autism Spectrum Screening Questionnaire (ASSQ), the Australian Scale for Asperger's Syndrome, and the most recent, the Childhood Asperger Syndrome Test (CAST), are some of the instruments that are reliable for identification of school-age children with Asperger syndrome or higher functioning autism. These tools concentrate on social and behavioral impairments in children without significant language delay.

\section{Comprehensive Diagnostic Evaluation}

The second stage of diagnosis must be comprehensive in order to accurately rule in or rule out an ASD or other developmental problem. This evaluation may be done by a multidisciplinary team that includes a psychologist, a neurologist, a psychiatrist, a speech therapist, or other professionals who diagnose children with ASD.

Because ASDs are complex disorders and may involve other neurological or genetic problems, a comprehensive evaluation should entail neurological and genetic assessment, along with in-depth cognitive and language testing. In addition, measures developed specifically for diagnosing autism are often used. These include the Autism Diagnosis Interview-Revised (ADI-R) and the Autism Diagnostic Observation Schedule (ADOS). The ADI-R is a structured interview that contains over 100 items and is conducted with a caregiver. It consists of four main factors-the child's communication, social interaction, repetitive behaviors, and age-of-onset symptoms. The ADOS is an observational measure used to "press" for socio-communicative behaviors that are often delayed, abnormal, or absent in children with ASD. 


\section{A Retrospective Study of the Autism Spectrum Disease (ASD): A Review of Literature and Management Techniques of ASD}

Another instrument often used by professionals is the Childhood Autism Rating Scale (CARS). It aids in evaluating the child's body movements, adaptation to change, listening response, verbal communication, and relationship to people. It is suitable for use with children over 2 years of age. The examiner observes the child and also obtains relevant information from the parents. The child's behavior is rated on a scale based on deviation from the typical behavior of children of the same age.

These are mainly western tools; in India recently National institute for the mentally handicapped developed a tool to assess autism by name Indian Scale for Assessment of Autism (ISAA). This tool can be administered on children of three to adulthood. The severity of the autism can be obtained by administering this scale.

Two other tests that should be used to assess any child with a developmental delay are a formal audio logic hearing evaluation and a lead screening. Although some hearing loss can co-occur with ASD, some children with ASD may be incorrectly thought to have such a loss. In addition, if the child has suffered from an ear infection, transient hearing loss can occur. Lead screening is essential for children who remain for a long period of time in the oral-motor stage in which they put any and everything into their mouths. Children with an autistic disorder usually have elevated blood lead levels.

Customarily, an expert diagnostic team has the responsibility of thoroughly evaluating the child, assessing the child's unique strengths and weaknesses, and determining a formal diagnosis.

\section{Associated Conditions}

In about 5 percent of autism cases, another disorder is also present. Studying this kind of cooccurrence helps researchers who are trying to pinpoint the genes involved in autism. Similar disorders or disorders with similar symptoms may have similar genetic origins. In cases of one disorder commonly occurring with another, it could be that one is actually a risk factor for the other. This kind of information can provide clues to what leads to autism.

Some of these co-occurring disorders include:

\section{Sensory Problems}

When children's perceptions are accurate, they can learn from what they see, feel, or hear. On the other hand, if sensory information is faulty, the child's experiences of the world can be confusing. Many ASD children are highly attuned or even painfully sensitive to certain sounds, textures, tastes, and smells. Some children find the feel of clothes touching their skin almost unbearable. Some sounds-, a ringing telephone, a sudden storm, cooker whistle will cause children irritation. 


\section{A Retrospective Study of the Autism Spectrum Disease (ASD): A Review of Literature and Management Techniques of ASD}

In ASD, the brain seems unable to balance the senses appropriately. Some ASD children are oblivious to extreme cold or pain. An ASD child may fall and break an arm, yet never cry. Another may bang his head against a wall and not wince, but a light touch may make the child scream with alarm.

\section{Mental Retardation}

According to the research studies 60 to $70 \%$ of children may have low intelligence levels. When tested, some areas of ability may be normal, while others may be especially weak. For example, a child with ASD may do well on the parts of the test that measure visual skills but earn low scores on the language subtests. It was observed that majority of children with autism have intellectual deficits.

\section{Seizures}

One in four children with ASD develops seizures, often starting either in early childhood or adolescence. Seizures, caused by abnormal electrical activity in the brain, can produce a temporary loss of consciousness, a body convulsion, unusual movements, or staring spells. Sometimes a contributing factor is a lack of sleep or a high fever.

\section{Fragile X syndromes}

This disorder is the most common inherited form of mental retardation. It was so named because one part of the $\mathrm{X}$ chromosome has a defective piece that appears pinched and fragile when under a microscope. Fragile X syndrome affects about two to five percent of people with ASD. It is important to have a child with ASD checked for Fragile X, especially if the parents are considering having another child. For an unknown reason, if a child with ASD also has Fragile $\mathrm{X}$, there is a one-in-two chance that boys born to the same parents will have the syndrome. The latest statistics are consistent in showing that $5 \%$ of people with autism are affected by fragile $\mathrm{X}$ and $10 \%$ to $15 \%$ of those with fragile $\mathrm{X}$ show autistic traits.

\section{Tuberous Sclerosis}

Tuberous sclerosis is a rare genetic disorder that causes tumors to grow in the brain as well as in other vital organs. It has a consistently strong association with ASD. 1 to 4 percent of people with ASD also have tuberous sclerosis.

\section{Management of ASD}

ASDs, similar to other neurodevelopment disabilities, are generally not "curable," and chronic management is required. Although outcomes are variable and specific behavioral characteristics change over time, most children with ASDs remain within the spectrum as adults and, regardless of their intellectual functioning, continue to experience problems with independent living, employment, social relationships, and mental health. The primary goals of treatment are to 


\section{A Retrospective Study of the Autism Spectrum Disease (ASD): A Review of Literature and Management Techniques of ASD}

minimize the core features and associated deficits, maximize functional independence and quality of life and alleviate family distress.

To date there is no cure for autism. However, there are a number of management strategies that can help people with autism to lead a better quality of life. There are two important aspects of management; one is that early intervention is important; another is that individualized and highly structured programmes give people with autism their best chance for progress.

Treatment of autism is usually multidisciplinary. Developmental and behavioural therapies are effective in dealing with children with ASD. In recent years, effective early intervention practices have reduced the devastating sequel of the disorder. It has been found that intervention such as applied behavioural analysis, speech and language therapy, physical and occupation therapy provided before age 3 in children with autism have a great impact on successful management (Scott, Myers and Plauche, 2007).

\section{Applied Behavior Analysis}

Applied behavior analysis (ABA) is the process of applying interventions that are based on the principles of learning derived from experimental psychology research to systematically change behavior and to demonstrate that the interventions used are responsible for the observable improvement in behavior. ABA methods are used to increase and maintain desirable adaptive behaviors, reduce interfering maladaptive behaviors or narrow the conditions under which they occur, teach new skills, and generalize behaviors to new environments or situations.

\section{Developmental Models}

Developmental models are based on use of developmental theory to organize hypotheses regarding the fundamental nature of ASDs and design approaches to address the deficits. The Denver model, for example, is based largely on remediating key deficits in imitation, emotion sharing, theory of mind, and social perception by using play, interpersonal relationships, and activities to foster symbolic thought and teach the power of communication.

\section{Speech and Language Therapy}

A variety of approaches have been reported to be effective in producing gains in communication skills in children with ASD. Didactic and naturalistic behavioral methodologies eg, Discrete trail teaching, verbal behavior, natural language paradigm, pivotal response training, milieu teaching have been studied most thoroughly and found to be effective in improving the communication of autistic children.

The use of augmentative and alternative communication modalities, including gestures, sign language, and picture communication programs, often are effective in enhancing communication. The Picture Exchange Communication System (PECS) is used widely. The PECS method 


\section{A Retrospective Study of the Autism Spectrum Disease (ASD): A Review of Literature and Management Techniques of ASD}

incorporates $\mathrm{ABA}$ and developmental pragmatic principles, and the child is taught to initiate a picture request and persist with the communication until the partner responds. Introduction of augmentative and alternative communication systems to nonverbal children with ASDs does not keep them from learning to talk, and there is some evidence that they may be more stimulated to learn speech if they already understand something about symbolic communication

\section{Social Skills Instruction}

There is some objective evidence to support traditional and newer naturalistic behavioral strategies and other approaches to teaching social skills. Joint attention training may be especially beneficial in young, preverbal children with ASDs, because joint attention behaviors precede and predict social language development.

A social skills curriculum should target responding to the social overtures of other children and adults, initiating social behavior, minimizing stereotyped preservatives behavior while using a flexible and varied repertoire of responses, and self-managing new and established skills. Social skills groups, social stories, visual cueing, social games, video modeling, scripts, peer-mediated techniques, and play and leisure curricula are supported primarily by descriptive and anecdotal literature are some of the methods through which the social skills of children with autism can be improved.

\section{Occupational and Sensory Integration Therapy}

Unusual sensory responses are common in children with ASDs. Traditional occupational therapy often is provided to promote development of self-care skills (egg, dressing, using utensils and personal hygiene) and academic skills (eg, cutting with scissors, writing). Occupational therapists also may assist in promoting development of play skills, modifying classroom materials and routines to improve attention and organization, and providing prevocational training. However, research regarding the efficacy of occupational therapy in ASDs is lacking. Sensory integration (SI) therapy often is used alone or as part of a broader program of occupational therapy for children with ASDs. The goal of SI therapy is not to teach specific skills or behaviors but to remediate deficits in neurological processing and integration of sensory information to allow the child to interact with the environment in a more adaptive fashion.

\section{Psychopharmacology}

Pharmacologic interventions may be considered for maladaptive behaviors such as aggression, self-injurious behavior, repetitive behaviors (eg, perseveration, obsessions, compulsions, and stereotypic movements), sleep disturbance, mood liability, irritability, anxiety, hyperactivity, inattention, destructive behavior, or other disruptive behaviors. In some cases, the diagnosis of a co morbid disorder, such as major depression, bipolar disorder, or an anxiety disorder, can be made reasonably and the patient can be treated with medications that are useful for treating these conditions in otherwise typically developing children and adolescents. 


\section{A Retrospective Study of the Autism Spectrum Disease (ASD): A Review of Literature and Management Techniques of ASD}

\section{Family Support}

Management should focus not only on the child but also on the family. Parents play a key role in effective management of ASD. Having a child with an ASD has a substantial effect on a family. Parents and siblings of children with ASDs experience more stress and depression than those of children who are typically developing or even those who have other disabilities.

Supporting the family and ensuring its emotional and physical health is an extremely important aspect of overall management of ASDs. Health care professionals can provide support to parents by educating them about ASDs; providing anticipatory guidance; training and involving them as co therapists; assisting them in obtaining access to resources; providing emotional support through traditional strategies such as empathetic listening and talking through problems; and assisting them in advocating for their child's or sibling's needs.

The need for support is longitudinal, although the specific needs may vary throughout the family life cycle. One of the chief strategies for helping families raise children with ASDs is helping to provide them with access to needed ongoing supports and additional services during critical periods and/or crises.

\section{REVIEW OF LITERATURE}

Study related ROL.

Jepsen (2002) examined the outcomes of incorporating mediated cognitive education into special education classrooms. Cognitive education provided cognitive training utilizing REHABIT materials through mediated teaching. Following a matched pair model, forty-six students were assigned to either a treatment or a control group. All students received weekly instruction in Individual Educational Program (IEP) goals. Curriculum areas included IEP objectives in reading, math, social skills, health, science and social studies. Students in the control group received regular classroom instruction. Students in the treatment group participated in cognitive educated one hour per week replacing thirty minutes of reading and thirty minutes of math. Pre and post test comparisons on measures of intelligence, achievement and adaptive behavior showed those students in the treatment group attained higher scores across measures.

Loke (2010) investigated that the effectiveness of whole word approach on learning to read and write words among children with autism. The sample consists of children with autism age ranging from 7 to 9 years. Sample was drawn from Shradha School, Rasoolpura, and Secunderabad. Size of the sample consists six subjects. The sample was selected on the basis of picture reading ability. Selected subjects were randomly assigned to Experimental and Control group. Each group consists of their subjects. For conducting the study pre-test Post-test control group design was used. The subjects in the experimental group taught to read and write words using whole word approach and subjects of control group were taught to read words using phonic approach and writing through conventional method. Intervention was carried out for 20 


\section{A Retrospective Study of the Autism Spectrum Disease (ASD): A Review of Literature and Management Techniques of ASD}

sessions. The results of the study indicated that there is a significant improvement in reading and writing words. From the results it is evident that the children who were taught to read and write using whole word approach shown higher performance than the children who were taught through conventional method.

Paul (2005) conducted the comparative study of the purpose for effectiveness and efficiency of static picture prompts and video modelling as classroom simulation strategies in combination with in vivo community drawing money from an ATM and purchasing items using a debit card. Both simulation strategies were effective and efficient at teaching the skills. The two simulation strategies were not functionally different in terms of number of trials to acquisition, number of errors, and number of instructional sessions to criterion.

\section{Study related in Communication \& Social}

Dawson (1999) Introduced the TEACCH approach in India context the main purpose of the study was to provide to autism child to learn through visual medium for the is reason researcher used child to learn through visual medium for the researcher used structure in mainly 3 area physical environment, time and activities the main focus was given on improving communication among children with autism. It was an associated object, activity, physical structure with scheduling through every practice and given initial prompt later go the prompt to make the independent all the four components were followed through this study finally research also needed different according to their loud and also suggested about consistency and persistence for there to be better result at the end it is mostly useful for learning.

Cassandra Holifield (2010) investigated that the effectiveness of a self-monitoring procedure on increasing attending to task and academic accuracy in two elementary students with autism in their self-contained classroom. A multiple baseline across participants in two academic subject areas was used to assess the effectiveness of the intervention. Both students were taught to selfmonitor in language arts and mathematics with measures of attending to task and academic accuracy being collected simultaneously. Results are interpreted to conclude that the selfmonitoring procedure was effective for both students and resulted in immediate increases in attending to task and academic accuracy even though results in academic accuracy were variable. Social validity was documented by the increase in two behaviors relevant for student success (attending to task and academic accuracy) and greater student independence.

Suryakala (2011) examine that Children with special needs often exhibit poor communication skills. They need to participate in situation through which they learn to express themselves. Therefore there is a need to use innovative methods for communication development (two words combinations) in children with intellectual disabilities. The study investigated the effect of play way method on improving communication skills among children with mild intellectual 


\section{A Retrospective Study of the Autism Spectrum Disease (ASD): A Review of Literature and Management Techniques of ASD}

disabilities. A total of five students with mild intellectual disability between the age group of 5 to 10 year studying in the pre-primary at

\section{Study related to retrospective study}

Carolyn Long (2011) investigated that the compare of cognitive skills of young children diagnosed with autism spectrum disorder (ASD) to same-aged peers referred for possible developmental delays or behavioral concerns using the Bayley Scales of Infant DevelopmentThird Edition. A retrospective chart review was conducted of 147 children ages 16 to 38 months who were referred to a diagnostic clinic for developmental evaluation. Children with ASD were compared to those without ASD with respect to cognition and language outcomes, both overall and by age. While language skills in children with ASD were more significantly delayed than language skills in children without ASD, there was less discrepancy in the cognitive skills of children with and without ASD. Formal cognitive assessment of children with ASD can provide guidance for developmental expectations and educational programming. Cognitive skills of children with ASD may be underappreciated.

Saidulu Reddipally (2011) investigated that the Epilepsy among children with intellectual disability retrospective study. The study was conducted of Out of total 3,153 registered cases, 644 case files of children below 6 years of age with Intellectual disability having epilepsy were selected for study. Data was collected from the case files diagnosed children with intellectual disability with epilepsy in General Services NIMH. The results were Prevalence of epilepsy among boys is more than girls.

* Consanguinity was not found as major risk factor.

* Onset of Epilepsy was found in substantial cases during birth to 1 month.

Amarjyothi Persha, Saroj Arya, Nagar, Behera, Verma, Kishore (2007) investigated that the Biological and Psychosocial Predictors of Developmental Delay in Persons with Intellectual Disability: Retrospective Case -File Study. The study was conducted at the National Institute for Mentally Handicapped (NIMH) Regional Centre, Kolkata, India. Data were collected from the case files. The sample was, out of 712 cases registered with the institute from Aug. 2004 to July 2005. The final sample was 438 cases of which majority were males (64.1\%).The results indicates Maternal age at conception, fatal presentation, neonatal seizures and infections were thaw best indicators of developmental delay.

* Psychosocial variables such as emotional trauma during pregnancy, economic status and education of parents had no significant impact on development.

Rout, Praveen, Chattopadhyay and Kishore (2008) Conducted study on risk factors of hearing impairment Indian children .A retrospective case file study at the Ali Yavar Jung National Institute for Hearing Handicapped, eastern Regional centre, Kolkata, India. The aim of the study 


\section{A Retrospective Study of the Autism Spectrum Disease (ASD): A Review of Literature and Management Techniques of ASD}

was to identify the association factors of hearing impairment in Indian children. The study included 1336 case files of children reported with hearing problems during 2003-2004. 336 were excluded owing to inadequate information or lack of reliable informant. The data taken from the case files are authentic, as the data were collected by the internees in audiology. Result of this study revealed that there were no significant difference in the main age of deduction of hearing impairment in boys and girls. Parental causes, exposure to x-rays during gestation, premature delivery, low birth weight, post natal jaundice, neo natal seizures and rubella were the significant predictors of hearing impairment. It is concluded that a large population was respiratory disease. Survivors in 2003 were in 1993 more competent in personal, self-help and motor activity and were less likely to have epilepsy.

Persha, Arya, Nagar, Behera, Verma \& Kishore (2007) Studied that the biological \& psychosocial predictors of developmental delay in person with mental retardation. Retrospective case files study. The purpose of the study was to find out the biological \& psychosocial predictors of developmental delay in person with mental retardation. The study was conducted at the NIMH regional Centre, Kolkata, India. Data were collected from the case file. The study consisted of reviewing of 438 files of person with mental retardation. Majorities were males $64.1 \%$ and the mean id was $8.17 \%$. Mild and moderate had equal distribution $31.7 \%$ which was followed by severe retardation $25.3 \%$. $100 \%$ of father had gainfully occupation or employment though only $82.4 \%$ were literate. Results indicated that maternal age at conception; fetal presentation; neo natal seizure and infection were the best indicator of the developmental delay of characteristics of mental retardation. Psychosocial variable such as emotional trauma during pregnancy, economic status and education of parents has no significant impact on development.

\section{OBJECTIVE}

The main objective of the reviewed studies, as the educational needs aspects focused on

$>\quad$ Enhancing Communication Skills.

$>\quad$ Enhancing Social skills.

$>\quad$ Studies on Retrospective focused.

\section{METHOD}

The word methodology is defined as a system which comprises the principles, practices and procedure which are applied to a specific branch of knowledge. Methodology includes the methods, techniques and procedures which are uses to collect and analyse the information. The present study is a qualitative research.

Qualitative researchers seek to understand a phenomenon by focusing on the total picture rather than breaking it down in to variable. The goal is a holistic picture and depth of understanding rather than a numeric analysis of data. In survey research investigators ask question about people's belief, opinions, characteristics, and behaviour. A survey researcher may want to 


\section{A Retrospective Study of the Autism Spectrum Disease (ASD): A Review of Literature and Management Techniques of ASD}

investigate association between respondents, characteristics such as age, education, social class, race, and their current attitudes towards some issue. Survey research typically does not make causal inferences but, rather, describes the distributions of variables in a specified group.

This research is a qualitative research which mainly focuses on understanding social phenomena from the perspective of human participants using retrospective method for collecting data to investigate the present study.

A retrospective cohort study uses the existing data that have been recorded for reasons other than research. A retrospective study, also called a historic cohort study.

\section{Retrospective study:}

The current study involves that the collecting of data about past events and studies. This design is mainly employed to measure and understand change and to include a time dimension to the data that can be used to identify causal factors contributing to any observed change. The capacity of a retrospective study to adequately defect change and ascertain causes depends on how well the investigator can reconstruct the past from the vantage point of the present.

The main purpose for collecting retrospective data is that such data provide mains of measuring change to either descriptive or explorative purposes.

\section{Research design:}

The present study is a retrospective study whereby the case files diagnosed as an ID with Autism Spectrum Disorder in General Services, NIMH were studies.

\section{Sample:}

Cases registered at the NIMH diagnosed as an ID with Autism Spectrum Disorder from the year Dec 2008 to 2011 Jan. The age range from 6 to 18 years old.

\section{Sample technique:}

Non - Probability, Purposive sampling technique was used to collect the data from the cases files of intellectual disability with Autism Spectrum Disorder in General Services, NIMH, Secunderabad.

\section{Inclusion Criteria}

- $\quad$ Only those case files which are diagnosed as intellectual disability with Autism Spectrum Disorder.

- $\quad$ Case files registered from Dec 2008 to 2011 Jan.

- $\quad$ Only case files 6 to 18 years were included.

\section{Exclusion criteria}

- $\quad$ That case file which was diagnosed borderline and average intellectual disability with Autism Spectrum Disorders.

- $\quad$ Case files registered before Dec 2008 and after 2011 Jan.

- Below 6 years and above 18 years case files exclusion. 


\section{A Retrospective Study of the Autism Spectrum Disease (ASD): A Review of Literature and Management Techniques of ASD}

\section{Tool:}

For the purpose of obtaining the objectives of the study the researcher used the following tools:-

- $\quad$ Researcher was developed a Master sheet for the study.

- $\quad$ Researcher was developed coding sheets collecting data for the study.

- $\quad$ Master sheet was prepared for compiling all the data. Computerised codes were given for the collecting data from the files.

\section{Setting}

The data was collected in General Service at NIMH Secunderabad.

\section{Procedure:}

The data was collected from the cases files. The information from the cases files is authentic as data was collected by multidisciplinary professionals having experience in the field of intellectual disability having ASD. The study was included review of case files from Dec 2008 to 2011 Jan. Total 100 cases files having children's intellectual disability with ASD. The files contain information about medical, psychological, and educational information anecdotal records. At the next level the information was verified and detailed assessment was conducted individually by a psychiatrist, a clinic psychologist and a special educator. Case files of individuals between 6 to 18 years. The case files contained information as per a standardized format developed by the institution. We are studied 100 records in depth collecting the details such as demographic data, communication skills, academics skills, socializations, educational status, provisional diagnosis, associated conditions, management and referral. The data collected has been coded and entered into Microsoft excel format.

\section{Statistical Analysis:}

The data was analysed using appropriate statistical tools. Percentages were calculated for the various characteristic. The statistical analysis was carried out using SPSS 16.0 version.

\section{RESULT AND DISCUSSION-}

In the view of Kothari (2001), the major part of report is result and discussion. It is an organized presentation of results of investigation. It includes the presentation of all data gathered which are relevant to the problem. The present study educational needs of Children having Intellectual Disability with Autism Spectrum Disorder. The present educational needs in relation to their age, gender, diagnosis and locality, onset of communication, reading, writing, arithmetic, socialization. There were taken 100 cases files diagnosed as an ID with Autism Spectrum Disorder registered at NIMH, General Services, Secunderabad from Dec 2008 to 2011 Jan.

This chapter analyses the various demographic details of children having ID with Autism Spectrum Disorder. 


\section{A Retrospective Study of the Autism Spectrum Disease (ASD): A Review of Literature and Management Techniques of ASD}

Table showing that characteristic of children's having ID with Autism Spectrum Disorder

\begin{tabular}{|c|c|c|}
\hline Variables & $\begin{array}{l}n \\
(N=100)\end{array}$ & $\%$ \\
\hline \multicolumn{3}{|l|}{ Age: } \\
\hline - 6 to 9 years & 86 & $86 \%$ \\
\hline - 10 to 13 years & 12 & $12 \%$ \\
\hline - 14 to 18 years & 2 & $2 \%$ \\
\hline \multicolumn{3}{|l|}{ Gender: } \\
\hline - Male & 84 & $84 \%$ \\
\hline - Female & 16 & $16 \%$ \\
\hline \multicolumn{3}{|l|}{ Diagnosis: } \\
\hline - $\quad$ Borderline ID having autism & 21 & $21 \%$ \\
\hline - $\quad$ Mild ID having autism & 32 & $32 \%$ \\
\hline - $\quad$ Moderate ID having autism & 37 & $37 \%$ \\
\hline - $\quad$ Severe ID having autism & 10 & $10 \%$ \\
\hline - $\quad$ Profound ID having autism & 0 & $0 \%$ \\
\hline \multicolumn{3}{|l|}{ Locality: } \\
\hline - Urban & 75 & $75 \%$ \\
\hline - Rural & 25 & $25 \%$ \\
\hline \multicolumn{3}{|l|}{ School History: } \\
\hline - $\quad$ Not attending & 24 & $24 \%$ \\
\hline - $\quad$ Attending special school & 21 & $21 \%$ \\
\hline - $\quad$ Regular school & 37 & $37 \%$ \\
\hline - $\quad$ Discontinued & 18 & $18 \%$ \\
\hline
\end{tabular}

Table depicts the characteristics of children having ID with Autism Spectrum Disorder. From the table we can observe that the majority (86\%) of clients with having ID with Autism Spectrum Disorder fall in the age group of 6 to 9 years, followed by $12 \%$ of client 10 to 13 years of age. $2 \%$ of client 14 to 18 years of age. This is not in line with the finding of Behere. P.B and Tripathi.K. (1981) where the second most majority age group of children with intellectual disability were between the age group of 11-16 years then below 5 years of age. The reason for this could be during the early years intellectual disability may be less obvious, and the slow developing child is more likely to be confined within the home and thus does not become known in the neighborhood. Parents may be disinclined to talk about the problem, hoping that the child is merely a late developer who will soon catch up. Another reason could be a minor delay may not be observed in the preschool age group may become quite apparent in school going age.

Children having ID with Autism Spectrum Disorder is high among males 84\% when compared to females $16 \%$. The present finding is in line with the finding of Quaisar, Jahan and Asari, on 


\section{A Retrospective Study of the Autism Spectrum Disease (ASD): A Review of Literature and Management Techniques of ASD}

psycho-economic factor associated with mental retardation where males have been found more prone towards having mental retardation then females and the similar findings have been reported by Misra. L.S, Saxena.N.K, Pathak.M.P 1981. One of the reason for this trend could be families in India prefer male children because men are viewed as future bread-winners and heir to the family name or could be the idea that soul of the dead remains at peace or goes ahead to its destination only if the last rituals are performed by a son of the dead only. Another reason could be parents want to protect the female's child by not exposing her limitations in the society.

Children having ID with Autism Spectrum Disorder is high Moderate ID having autism (37\%). 32\% Mild ID having autism. 21\% Borderline ID having autism. 10\% Severe ID having autism.

Children having ID with Autism Spectrum Disorder is high urban 75\%. 25\% rural children having ID with Autism Spectrum Disorder. Majority (75\%) cases of children having ID with Autism Spectrum Disorder registered are from urban area. The possible reason for this could be, due to growing awareness among urban population and may be to the location of the institute at Hyderabad. Another reason may be due to lack of awareness about the institute in rural areas.

While $84 \%$ of the sample were male and $16 \%$ of sample were female. Only $21 \%$ of children having ID with Autism Spectrum Disorder were attending in special school. 37\% of children having ID with Autism Spectrum Disorder attending regular school, and 18\% of them have discontinued. Only $24 \%$ of clients were not attending any school. As per the zero rejection policy under Sarva Shiksha Abhiyan, children with disability can be also taught and trained in normal school as part of inclusive education programme. The reason for this trend could be special school may not be giving admission because of the critical condition of children having ID with Autism Spectrum Disorder. Any other reason could be school may require a variety of support services and such kind of services may not available to meet the educational needs of children having ID with Autism Spectrum Disorder.

\section{IMPLICATIONS OF THE STUDY}

The present study implied various educational needs in children having ID with Autism Spectrum Disorders registered at NIMH Secunderabad. The study results can be implicated in finding the educational needs in children having ID with Autism Spectrum Disorders.

- The study can be useful to provide the needful information on educational needs in children having ID with Autism Spectrum Disorders registered NIMH and its severity level, onset of age at among children having ID with Autism Spectrum Disorders.

- Service models can be set up to create on educational needs in children having ID with Autism Spectrum Disorders.

- Special education teachers can plan their program in consultant with speech therapist to enhance their communication skills to integrate in the individualized education program. 


\section{A Retrospective Study of the Autism Spectrum Disease (ASD): A Review of Literature and Management Techniques of ASD}

- Special education teachers can plan their program better in reading, writing and arithmetic and to enhance all these skills to integrate in the individualized education program.

- Detailed assessment can be done using the results to find socialization deficits and provide one to one instruction to facilitate maximum learning in social skills.

- Early educational needs programs can be helpful in preventing secondary education and to bring maximum results during the early period.

- Onset of educational needs cautions the professionals to deal and provide information on the early onset so that preventive measures can be taken up.

- The study reveals that there is a need to be given to staff to advance their knowledge and skills for educational needs in children having ID with Autism Spectrum Disorders.

- The study more emphasis for educational needs among children having ID with Autism Spectrum Disorders improving services, teaching strategies, self-help skills, communication and academic skills for the children having ID with Autism Spectrum Disorders.

- The study also reveals to bring awareness among parents and teacher on educational needs availing special education as well as reading, writing, academic and socialization skills among children having ID with Autism Spectrum Disorders.

- Parents can also make useful by teaching day to day in the functional skills such as reading, writing, academic and socialization skills.

\section{LIMITATIONS OF THE STUDY:}

- The present study has few limitation respect to its sample as it excluded borderline and average intellectual disability with Autism Spectrum Disorders including mild to severe having intellectual disability with Autism Spectrum Disorders.

- The study was limited to having intellectual disability with Autism Spectrum Disorders.

- Only Dec 2008 to 2011 Jan case file has been studies as the results cannot be generalization.

- Only 3-18years. Diagnosed having ID with ASD case Jan case file has been studies.

\section{SCOPE FOR FUTURE RESEARCH:}

- Future research can also be on educational needs having other associated disability.

- Similar studies can be conducted on educational needs among adults with intellectual disability with other disabilities.

- A study can be conducted to compare on educational needs among male and female with intellectual disability with other disabilities.

- Future study can be conducted on home based educational needs, early education children having ID with Autism Spectrum Disorders.

- The future research may be conducted with a large sample for better generalization.

- The future research may be conducted vocational needs children having ID with Autism Spectrum Disorders. 


\section{A Retrospective Study of the Autism Spectrum Disease (ASD): A Review of Literature and Management Techniques of ASD}

\section{SUMMARY AND CONCLUSION}

The present study is a retrospective study whereas case files diagnosis as having ID with Autism Spectrum Disorders registered at General Services NIMH Secunderabad, were studied in detail. The present study aimed to find out the "Educational needs in Children having Intellectual Disability with Autism Spectrum Disorder" with reference to the age, gender and severity of disability, locality registered during Dec 2008 to 2011 Jan case file registered at General Services NIMH Secunderabad.

This research is a qualitative research which mainly focuses on educational needs in children having Intellectual Disability with Autism Spectrum Disorder registered case files from NIMH using retrospective method for collecting data to investigate the present study. This ability to educational needs can help any individual to increase functional skills. These way educational skills will enhance knowledge, social skills, reading, writing, communication etc. Educational involves the recognition of printed text and comprehension of that text as meaningful information.

\section{REFERENCES:}

Guldberg, K. (2010). Educating children on the Autism Spectrum: Preconditions for inclusion and notions of 'best autism practice' in the early years. British Journal of Learning Disabilities, 37(4), 168-172.

Narayan, J. (2003). Educational of Persons with Autism Spectrum Disorders. KARAVALAMBAN, 16, 9-13 NIMH, Secunderabad.

Rao, V.R.P.S. (December, 2003). Autism: A Challenge in Education. KARAVALAMBAN, Vol16.issue.3, 14-15, NIMH Secunderabad.

Meir, A. k., Schlosser, R.W., Elli, J.K., Harrington, C., \& Carter, B. (2008). Effects of iconicity on requesting with the Picture Exchange Communication System in children with autism spectrum disorder. Research in Autism spectrum disorders, 2(208), 430-446.

Thomson, K., Garry, Martin, G.L., Arnal, L., Fazzio, D., \& YU, C.T. (2009).Instructing individual to deliver desert-trials teaching to children with autism spectrum disorder: A review. Research in Autism Speech Disorder, 3, 590-606.

Daniela, F., \& Martin, G.L., (2009). Instructing University students to conduct discrete-trials teaching with children with autism. Research in Autism Spectrum Disorders, Vol.3 (1).5766.

Angelo. P., Roger. (2008). Teaching students with autism spectrum disorders. United States of America: George Giuliani., mnbvcxzm.

Sherratt, D.”Developing pretend play in children with autism: a case study.” Autism 2002 Jun, .6(2):169-79.

Jahar, E., Eikeseth, S. “Teaching children with autism to initiate and sustain cooperative play.” Res Dev. Disable 200pr, 21(2):151-69. 


\section{A Retrospective Study of the Autism Spectrum Disease (ASD): A Review of Literature and Management Techniques of ASD}

Shabani, D.B., Katz, R.C., Wilder, D.A., Beauchamp, K., Taylor, C.R., Fischer, and K.J. "Increasing social initiations in children with autism: effects of a tactile prompt." $J$ Appl Behav Anal 2002 spring; 35(1):79-83. Publication Types: Clinical Trial.

Thiemann, K.S., Goldstein, H. "Social stories, written text cues, and video feedback: effects on social communication of children with autism.” J Appl Behav Anal 2001 Winter; 34(4): 42546. Publication Types: Clinical Trial.

Laushey, K.M., Heflin, L.J. "Enhancing social skills of Kindergarten children with autism through the training of multiple peers as tutors."

Moore, M., Calvert, S. "Brief report: vocabulary acquisition for children with autism: teaching or computer instruction.” J Autism Dev Disord 2002 Aug; 30(4):359-62.

Kasari, C., Freeman, S.F., Bauminger, N., Alkin, M. C. "Parental perspectives on inclusion: effects of autism and Down syndrome.” J Dev Disord 1999 Aug; 29(4):297-305.

Taylor, B.A., Levin, L. “Teaching a student with autism to make verbal initiations: effects of a tactile prompt."

Vacca, J.S. (2007). Autistic children can be taught to read. International Journal of Special education, 22(3).

Chiang, H.M., \&Lin, H.Y. (2007). Reading Comprehension Instruction for students with Autism Spectrum disorder. A review of literature. Focus on Autism and Other Development Disability, 22(4), 261-267.

Laarhoven, T.V., Kraus, E., Karpman, K., Nizzi, R., \& Valention, J. (2010).A comparison of Picture and Video Prompts to Teach Daily Living Skills to Individual with Autism. Focus on Autism and Other Development Disabilities, 21(4), 195-208.

Machalicek, W., Reilly, M., Chan, J.M., Rispoli, M., Lang, K., Davis, T., Shogren, K., Sorrells. A., Lancioni, G., Singafoods, J., Green, V., Lang., P. et al. (2009). Using Video conferencing to support teacher to conduct preference assessment with autism and developmental disabilities. Research in Autism Spectrum Disorders, 3, 22-41

Klein, J.K., MacDonald, R.P.F., Vaillancourt, G., AHEARN, W.H., \& Dube, W.V. (2009).Teaching discrimination of adult gaze direction to children with autism. Research in Autism Spectrum Disorder, 3, 42-49.

Laarhaoven, T.V., Kraus, E., Karman, K., Nii, R., \&Valenfino, J. (2010). A Comparison of Picture and Vide Prompts to Teach Daily Living Skills to Individuals With Autism. Focus on Autism and Other Developmental Disabilities, 21(4), 195-208.

Anger, k., Schosser, R.W., Luiselli, J.K, Harrington, C., \& Carter, B. (2008). Effects of iconicity on requesting with the Picture Exchange Communication System in children with autism spectrum disorder. Research in Autism Spectrum Disorder, 2 (208), 430-446.

White, S.W., Koenig, K., \& Scahill, L. (2010).Group Social Skill Instruction for Adolescents with High- Functioning Autism Spectrum Disorder. Focus on Autism and Other Development Disabilities, 25(4), 209-219. 


\section{A Retrospective Study of the Autism Spectrum Disease (ASD): A Review of Literature and Management Techniques of ASD}

Holifield, C., Goodman, J., Hazelkorn, M., \& Hefilm, L. J. (2010). Using Self-Monitoring to Increase Attending to Task and Academic Accuracy in Children With Autism. Focus on Autism Other Developmental Disabilities, 25(4), 230-238.

Mancil, G.R. (2009). Milieu therapy as a Communication Intervention: A Review of the Literature Related to Children with Autism Spectrum Disorder. Education and Training in Developmental Disabilities, 44(1), 105-177.

Flores, M.M. (2009). Effects of Direct Instruction on the Reading Comprehension of Students with Autism Developmental Disabilities.Education and Training in Developmental Disabilities, 44(1), 39-53.

Dillenburger, k., Keenan, M., Doherty, A., Byrne, T., \& Gallagher, S. (2010). British Journal of Special Education, 37(1), 13-25.

Kurth, J., \& Mastergeorge, A.M. (2010). Individual Education Plan Goals and Services for Adolescents With Autism: Impact of Age and Educational Setting. The Journal of Special Education, 44(3), 146-160.

Pennington, R.C. (2010). Computer-Assisted Instruction for Teaching Academic Skills to Students With Autism Spectrum Disorders: A Review of Literature. Focus on Autism and Other Developmental Disabilities, 25(4), 329-248.

Howlin, P. (2005). Autism Preparing for Adulthood. New York.

Habury, M. (2005).Educating Pupils with Autism Spectrum Disorder. A Practical Guide. London: Thosand Oaks.

Pierangelo, R., \& Giuliani, G. (2008).Teaching Students with Autism Spectrum Disorder. London: Thosand Oaks.

ShebaRani, K.B. (2011). Current Status of Persons with Profound Intellectual Disabilities-A Retrospective Study (Unpublished Master Thesis). NIMH, Secunderabad.

\section{Websites:}

1) http:// www.autismresearchinstitute.com

2) http: // www.autism-society.org

3) http:// www.autismbc.ca

4) http:// www.jkp.com

5) http:// www.autismtreatment.info

6) http:// Wikpedia.org/Wiki/Autis

7) http:// www.ed.gov.com

8) http:// www.teach.com/com/attachments/resrepo.Pdf

9) http:// www.naset.org/Autism

10) http:// www.medicinenet.com

How to cite this article: R Chaudhary (2016), A Retrospective Study of the Autism Spectrum Disease (ASD): A Review of Literature and Management Techniques of ASD, International Journal of Indian Psychology, Volume 3, Issue 3, No. 6, DIP: 18.01.110/20160303 